\title{
Kinetics of Oxidation of L-Leucine by Mono- and Bimetallic Gold and Silver Nanoparticles in Hydrogen Peroxide Solution
}

\author{
P. VENKATESAN, J. SANTHANALAKSHMI ${ }^{*}$ \\ Department of Physical Chemistry, University of Madras, Guindy Campus, A. C. Tech, Chennai 600 025, Tamil Nadu, India
}

\begin{abstract}
The catalytic activity of surfactant stabilized mono- and bimetallic Au and Ag nanoparticles for the oxidation of an amino acid, L-leucine, was studied using hydrogen peroxide as the oxidant. The Au and Ag nanoparticle catalysts exhibited very good catalytic activity and the kinetics of the reaction were found to be pseudo-first order with respect to the amino acid. The effects of several factors, such as oxidant concentration, ionic strength, $\mathrm{pH}$, and catalyst concentration on the reaction, were also investigated. In particular, optimal oxidant and catalyst concentrations were determined. Very high concentrations of the metal nano-catalysts or the oxidant led to a dramatic increase in reaction rate. Moreover, bimetallic Au-Ag catalysts provided higher selectivity than pure Au or Ag.
\end{abstract}

Key words: gold nanoparticle; silver nanoparticle; gold/silver bimetallic nanoparticle; oxidation of $\alpha$-amino acid; leucine; hydrogen peroxide; kinetic study

CLC number: O643 Document code: A

Received 30 November 2011. Accepted 27 April 2012.

*Corresponding author.Tel: +91-44-22202816; E-mail: jslakshmi@yahoo.co.in

English edition available online at Elsevier ScienceDirect (http://www.sciencedirect.com/science/journal/18722067).

Amino acids are the precursors of essential bio-molecules, such as proteins, hormones, enzymes, etc. They are liable to lose their amino functional groups by two pathways: transamination or oxidative deamination. The pathway of oxidative deamination is shown in Scheme 1 [1,2].

Hydrogen peroxide $\left(\mathrm{H}_{2} \mathrm{O}_{2}\right)$ is one of the most powerful oxidizers known - stronger than chlorine, chlorine dioxide, and potassium permanganate [3]. $\mathrm{H}_{2} \mathrm{O}_{2}$ is a natural metabolite of many organisms, which decompose it to produce oxygen and water [4]. In addition, $\mathrm{H}_{2} \mathrm{O}_{2}$ is a highly effective oxidant for various oxidation reactions of both organic [5-13] and inorganic compounds [14,15]. Substances that are more difficult to oxidize may require the $\mathrm{H}_{2} \mathrm{O}_{2}$ to be activated with catalysts, such as iron, copper, manganese, or other transition metals [16]. These catalysts may also be used to accelerate $\mathrm{H}_{2} \mathrm{O}_{2}$ reactions that may otherwise take hours or days to complete. $\mathrm{H}_{2} \mathrm{O}_{2}$ catalysis may occur either in solution (using soluble catalysts) or in packed columns (using solid catalysts). The kinetics of oxidation of organic compounds by $\mathrm{H}_{2} \mathrm{O}_{2}$ catalyzed by metal complexes has previously been reported [17-19]. Moreover, the decomposition of $\mathrm{H}_{2} \mathrm{O}_{2}$ catalyzed by various mono- and bimetallic nanoparticles (NPs) was reported recently from our laboratory [20]. Therefore, it is of great interest to study metal nanoparticle catalyzed oxidation of amino acids using $\mathrm{H}_{2} \mathrm{O}_{2}$.

In this paper, we demonstrate the efficacy of surfactant stabilized monometallic gold, silver, and bimetallic gold/silver nanoparticle catalysts for the oxidation of L-leucine under a range of different experimental conditions.

\section{Experimental}

\subsection{Preparation of monometallic gold and silver nanoparticles}

$\mathrm{Au}$ and $\mathrm{Ag}$ metal nanoparticles were prepared using a wet chemical method, similar to that previously described by our group [20]. The metal salt solutions used consisted of $\mathrm{HAuCl}_{4}$ (Ranbaxy Ltd., India) and $\mathrm{AgNO}_{3}$ (Ranbaxy Ltd., India) for preparing $\mathrm{Au}$ and $\mathrm{Ag}$ nanoparticles, respectively. A $1.32 \mathrm{mmol} / \mathrm{L}$ metal salt stock solution was prepared and sonicated to facilitate complete dissolution. To $15 \mathrm{ml}$ of this solution, $10 \mathrm{ml}$ of $0.1 \mathrm{~mol} / \mathrm{L}$ cetyltrimethylammonium bro-<smiles>N=C(Cc1cnc(-c2ncc(CC(=O)C(=O)O)[nH]2)[nH]1)C(=O)O</smiles>

Scheme 1. Oxidative deamination of histidine. 
mide (CTAB, Aldrich) solution was added and the mixture stirred for $50 \mathrm{~min}$. The temperature of the solution was raised to $75{ }^{\circ} \mathrm{C}$ using a thermostat and a small volume of 0.1 $\mathrm{mol} / \mathrm{L} \mathrm{NaBH}_{4}$ solution (Aldrich, $3 \mathrm{ml}$ and $1 \mathrm{ml}$ for $\mathrm{Au}$ and $\mathrm{Ag}$, respectively) was added dropwise under cold conditions $\left(5{ }^{\circ} \mathrm{C}\right)$. Stirring was continued for a further $45 \mathrm{~min}$. The color of the solution changed from yellow to pink indicating the presence of Au nanoparticles. A UV-Vis spectrum of the solution was taken after nanoparticle formation. The presence of the surface plasmon resonance (SPR) peak at 520 $\mathrm{nm}$ confirms the formation of $\mathrm{Au}$ nanoparticles. In the case of $\mathrm{Ag}$, the color of the solution changed to yellow indicating the presence of $\mathrm{Ag}$ nanoparticles, which is confirmed by the UV-Vis spectra showing an SPR peak at $412 \mathrm{~nm}$.

\subsection{Preparation of gold-silver bimetallic nanoparticles}

Au-Ag metal nanoparticles were prepared by a wet chemical method with the $\mathrm{Au}^{3+}$ and $\mathrm{Ag}^{+}$mixture being reduced using a similar method to that previously described by our group [20]. Equal volumes $(5 \mathrm{ml})$ of $1.32 \mathrm{mmol} / \mathrm{L}$ solutions of $\mathrm{HAuCl}_{4}$ and $\mathrm{AgNO}_{3}$ were mixed maintaining a $1: 1$ molar ratio of $\mathrm{Au}: \mathrm{Ag}$. We then added $10 \mathrm{ml}$ of 1.0 $\mathrm{mmol} / \mathrm{L} \mathrm{CTAB}$ solution and stirred the mixture for $30 \mathrm{~min}$. $4.0 \mathrm{ml}$ of $0.1 \mathrm{~mol} / \mathrm{L} \mathrm{NaBH}_{4}$ cold solution $\left(5^{\circ} \mathrm{C}\right)$ was added dropwise with continuous stirring at an elevated temperature of $80^{\circ} \mathrm{C}$. The color of the solution changed from deep red to yellow to finally to dark brown within a few minutes. The solution was stirred for $60 \mathrm{~min}$ at $80^{\circ} \mathrm{C}$. The complete synthesis of the bimetallic nanoparticles is confirmed by the UV-Vis spectrum. The mono- and bimetallic nanoparticles synthesized in the present work are stable over an extended period of several months.

\subsection{Characterization}

TEM analysis was performed on a JEOL model 1200 EX instrument operated at an accelerating voltage of $120 \mathrm{kV}$. For HRTEM analysis, a drop of the respective colloidal solution was placed onto a Formvar stabilized copper grid and allowed to dry for $2 \mathrm{~h}$. Powder X-ray diffraction (XRD) analysis was carried out using a Philips PW 1050/37 diffractometer operating at $40 \mathrm{kV}$ and $30 \mathrm{~mA} . \mathrm{Cu} K_{\alpha}$ radiation with a wavelength of $0.154 \mathrm{~nm}$ and a step size of $0.02^{\circ}$ in the $2 \theta$ range of $30^{\circ}-80^{\circ}$ was used. A Shimadzu UV-1601 double beam spectrometer was used with $1 \mathrm{~cm}$ path length quartz cuvettes for acquiring UV-Vis spectra.

\section{$1.4 \alpha$-Amino acid oxidation}

The oxidative deamination of L-leucine, catalyzed by different nanoparticles synthesized, was performed in the presence and absence of $\mathrm{H}_{2} \mathrm{O}_{2}$. The kinetics of the $\alpha$-amino acid deamination reaction can be easily followed spectrophotometrically to study catalytic performance. The intensity of the absorption band at time, $t$, is proportional to the $\alpha$-amino acid concentration in solution.

\section{Results and discussion}

\subsection{Metal nanoparticle characterization results}

The UV-Vis absorption spectra of CTAB stabilized monometallic $\mathrm{Au}, \mathrm{Ag}$, and bimetallic $\mathrm{Au}-\mathrm{Ag}$ core-shell nanoparticles were recorded during the reduction process (Fig. 1). Figure 1(1) and (2) are the spectra obtained from the $\mathrm{Au}$ and $\mathrm{Ag}$ nanoparticles prepared under similar conditions. The maximum absorption of $\mathrm{Au}$ and $\mathrm{Ag}$ is around 532 and $420 \mathrm{~nm}$, respectively. Figure 1(3) is obtained from a dispersion prepared from a 1:1 mixture of $\mathrm{Au}$ and Ag solutions. For spherical Au and Ag nanoparticles, SPR usually takes place in the visible range with a maximum at $498 \mathrm{~nm}$. However, this can be shifted to the near-IR for certain non-spherical geometries and surface modifications. For example, because plasmon resonance is a surface effect, for core-shell particles the deposition of a second metal overlayer can completely change the resonance condition and alter the color of the nanoparticle dispersion. This is precisely what was observed for the core-shell nanoparticle colloids reported here, as seen in Fig. 1(3). While the starting Au colloid solution was deep red, upon deposition of a Ag shell it initially turned yellow and then, within a few minutes, changed to dark brown. This spectacular color change correlates well with large shifts of the corresponding UV-Vis spectra after each deposition step.

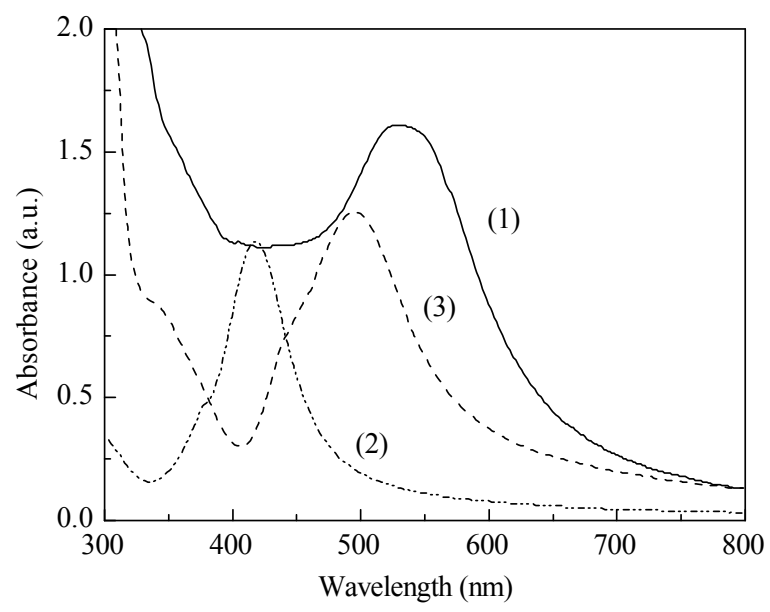

Fig. 1. Typical UV-Vis spectra of $\mathrm{Au}$ (1), $\mathrm{Ag}$ (2), and $\mathrm{Au}-\mathrm{Ag}$ (3) nanoparticles with a CTAB capping agent in aqueous media at $25^{\circ} \mathrm{C}$.

Figure 2 shows representative HRTEM images of the surfactant stabilized monometallic $\mathrm{Au}, \mathrm{Ag}$, and bimetallic 

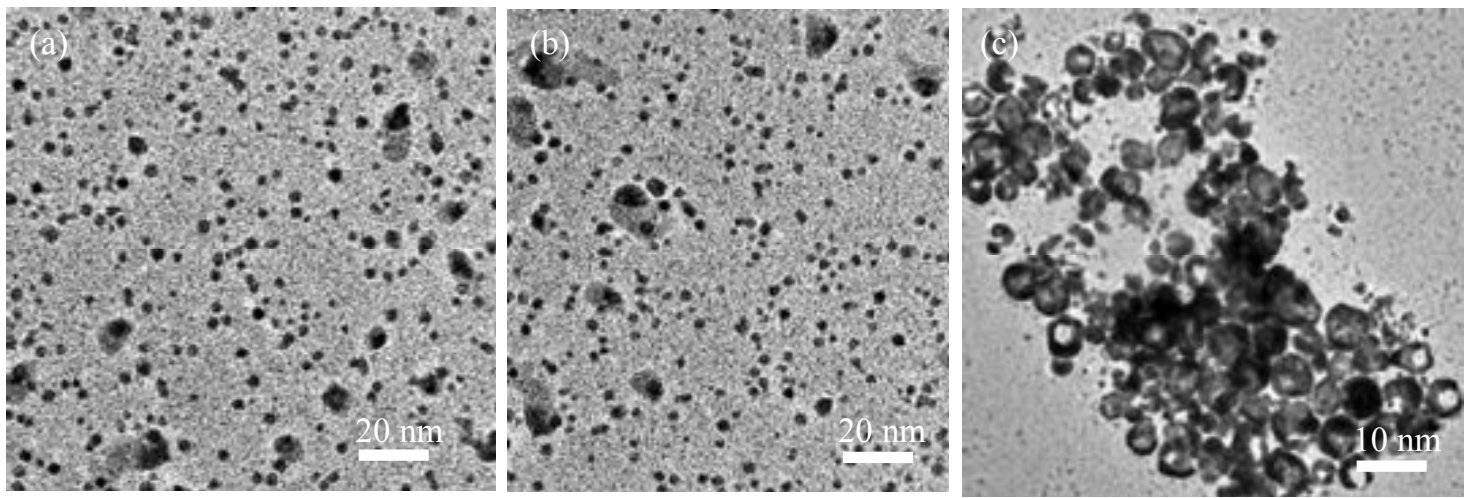

Fig. 2. HRTEM images of the monometallic $\mathrm{Au}(\mathrm{a}), \mathrm{Ag}$ (b), and bimetallic $\mathrm{Au}-\mathrm{Ag}$ nanoparticles (c).

$\mathrm{Au}-\mathrm{Ag}$ nanoparticles. It can be seen that the nanoparticles are monodisperse with average sizes of 8.6, 6.2, and $12.4 \pm$ $0.2 \mathrm{~nm}$ for $\mathrm{Au}, \mathrm{Ag}$, and $\mathrm{Au}-\mathrm{Ag}$, respectively.

The XRD patterns of the mono- and bimetallic nanoparticles are given in Fig. 3, indicating that the crystalline phase of the metallic nanoparticles is present with a face centered cubic structure. The particle size, as obtained from the XRD measurements, is also found to be monodisperse with average sizes of $8.4,6.4$, and $12.2 \mathrm{~nm}$, corresponding to monometallic $\mathrm{Au}, \mathrm{Ag}$, and bimetallic $\mathrm{Au}-\mathrm{Ag}$, respectively. CTAB in this reaction acts as a stabilizing agent for the particles in aqueous solution. Surfactants not only impart stability to the metal nanoparticles but also control their size and shape [21-23].

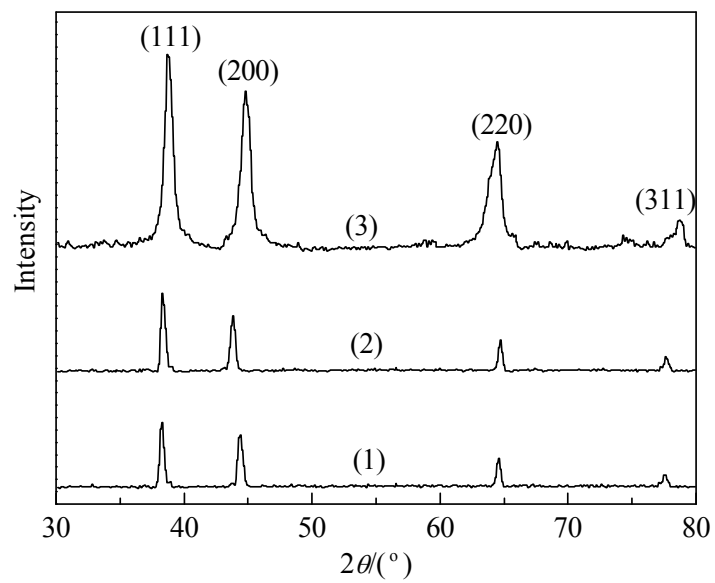

Fig. 3. XRD patterns of monometallic $\mathrm{Au}(1), \mathrm{Ag}(2)$, and bimetallic Au-Ag nanoparticles (3).

\subsection{Kinetic study for oxidation of L-leucine in the presence of metal nanoparticle catalysts}

The evolution of $\mathrm{H}_{2} \mathrm{O}_{2}$ decomposition and the oxidation of the amino acid catalyzed by Au nanoparticles were followed by UV-Vis spectroscopy. Specifically, the kinetics of the redox reaction were monitored based on the time-dependent optical density (OD) values at the $\lambda_{\max }$ of L-leucine. The derived kinetics plots are best fitted as pseudo-first order. Plots of $\log \mathrm{OD}_{t} / \mathrm{OD}_{0}$ as functions of time were made and the values of the slopes were used to determine the rate constants. $\mathrm{OD}_{0}$ and $\mathrm{OD}_{t}$ are the absorbance values at the $\lambda_{\max }$ of L-leucine at time $t=0$ and $t$. In the presence of the metal nanoparticles, the L-leucine absorption band was red shifted, which indicates the absorption of the amino acid onto the particles. Moreover, the absorbance value decreased gradually indicating that deamination took place. In the absence of metal nanoparticles, there was no sign of deamination on the experimental time scale.

\subsection{Effect of hydrogen peroxide concentration}

The metal nanoparticle catalyzed $\mathrm{H}_{2} \mathrm{O}_{2}$ decomposition and L-leucine deamination were studied in different $\mathrm{H}_{2} \mathrm{O}_{2}$ concentrations varying between $1 \times 10^{-5}-3 \times 10^{-5} \mathrm{~mol} / \mathrm{L}$. The rate constant increased by increasing the $\mathrm{H}_{2} \mathrm{O}_{2}$ concentration in the presence of the metal nanoparticles (Fig. 4 and Table 1, entries 2-5).

\subsection{Effect of L-leucine concentration}

The results presented in Table 1 (entries 6-10) show that for the decomposition of $\mathrm{H}_{2} \mathrm{O}_{2}$, the rate increases with an increase in the initial L-leucine concentration. The effect of $\alpha$-amino acid concentration on the decomposition of $\mathrm{H}_{2} \mathrm{O}_{2}$ can be well described by a non-competitive LangmuirHinshelwood kinetic equation. A straight line is obtained with a good correlation coefficient by plotting $1 / V_{0}$ against $1 /[\mathrm{AA}]_{0}$. The slope of the linear plot gives $k_{\mathrm{AA}}$ in $\mathrm{s}^{-1}$ (Fig. $5)$. It can be seen that the reaction rate increased rapidly in presence of metal nanoparticles.

\subsection{Effect of gold nanoparticle concentration}

The rate of the reaction is pseudo-first order with respect 


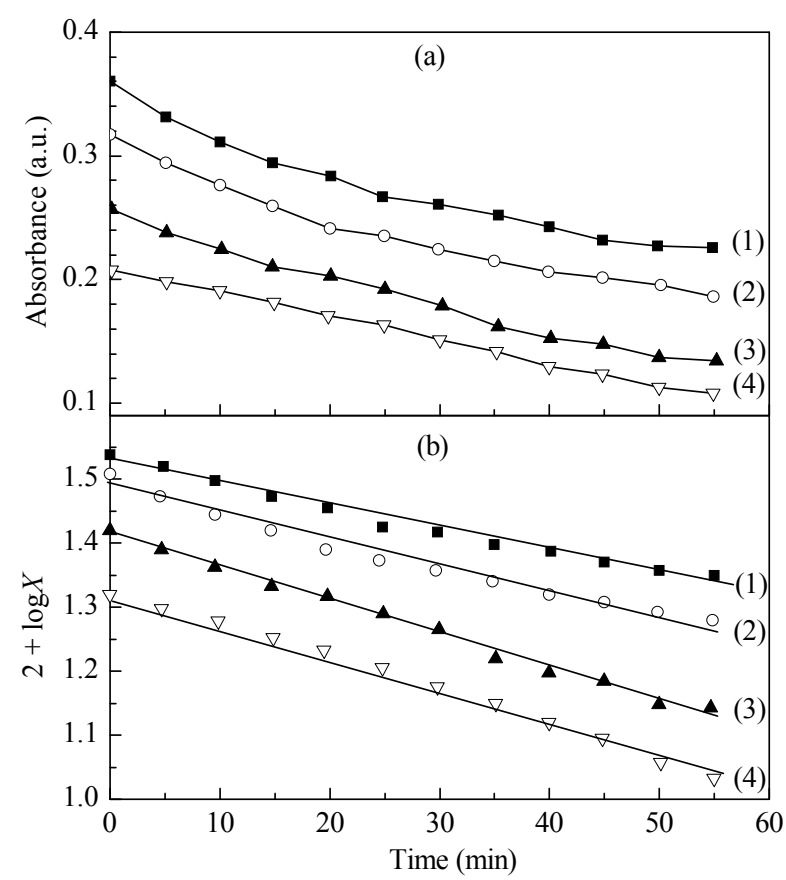

Fig. 4. Absorbance as a function of time (a) and kinetics plots for the deamination of L-leucine (b) in the presence of Au nanoparticle catalyst in aqueous media at $25{ }^{\circ} \mathrm{C}$ at different $\mathrm{H}_{2} \mathrm{O}_{2}$ concentrations. $\mathrm{H}_{2} \mathrm{O}_{2}$ concentration (mol/L): (1) $2 \times 10^{-5}$; (2) $3 \times 10^{-5}$; (3) $4 \times 10^{-5}$; (4) $5 \times$ $10^{-5}$. Reaction conditions: L-leucine $2 \times 10^{-7} \mathrm{~mol} / \mathrm{L}$, Au NPs $1 \times 10^{-3}$ $\mathrm{mol} / \mathrm{L}, \mathrm{pH}=7.0$.

Table 1 Pseudo-first order rate constants for the $\mathrm{Au}$ nanoparticle catalyzed deamination of L-leucine in aqueous media at $25^{\circ} \mathrm{C}$

\begin{tabular}{|c|c|c|c|c|c|c|}
\hline Entry & $\begin{array}{c}\mathrm{H}_{2} \mathrm{O}_{2} \\
\left(10^{-5}\right. \\
\mathrm{mol} / \mathrm{L})\end{array}$ & $\begin{array}{c}\text { L-Leucine } \\
\left(10^{-7} \mathrm{~mol} / \mathrm{L}\right)\end{array}$ & $\begin{array}{c}\text { Au NPs } \\
\left(10^{-3}\right. \\
\mathrm{mol} / \mathrm{L})\end{array}$ & $\mathrm{pH}$ & $\begin{array}{c}\text { Salt } \\
\left(10^{-4}\right. \\
\mathrm{mol} / \mathrm{L})\end{array}$ & $\begin{array}{c}k / \\
\left(10^{-2}\right. \\
\left.\mathrm{s}^{-1}\right) \\
\end{array}$ \\
\hline 1 & 2 & 2 & - & 7.0 & - & - \\
\hline 2 & 2 & 2 & 1 & 7.0 & - & 2.99 \\
\hline 3 & 3 & 2 & 1 & 7.0 & - & 3.14 \\
\hline 4 & 4 & 2 & 1 & 7.0 & - & 3.68 \\
\hline 5 & 5 & 2 & 1 & 7.0 & - & 4.00 \\
\hline 6 & 2 & 1 & 1 & 7.0 & - & 2.51 \\
\hline 7 & 2 & 2 & 1 & 7.0 & - & 3.04 \\
\hline 8 & 2 & 3 & 1 & 7.0 & - & 3.44 \\
\hline 9 & 2 & 4 & 1 & 7.0 & - & 3.38 \\
\hline 10 & 2 & 5 & 1 & 7.0 & - & 3.92 \\
\hline 11 & 2 & 2 & 1 & 7.0 & - & 3.28 \\
\hline 12 & 2 & 2 & 2 & 7.0 & - & 3.57 \\
\hline 13 & 2 & 2 & 3 & 7.0 & - & 3.09 \\
\hline 14 & 2 & 2 & 4 & 7.0 & - & 3.48 \\
\hline 15 & 2 & 2 & 5 & 7.0 & - & 3.72 \\
\hline 16 & 2 & 2 & 1 & 5.2 & - & 3.00 \\
\hline 17 & 2 & 2 & 1 & 7.0 & - & 3.18 \\
\hline 18 & 2 & 2 & 1 & 9.3 & - & 3.57 \\
\hline 19 & 2 & 2 & 1 & 7.0 & 1 & 3.00 \\
\hline 20 & 2 & 2 & 1 & 7.0 & 2 & 3.48 \\
\hline 21 & 2 & 2 & 1 & 7.0 & 3 & 3.96 \\
\hline 22 & 2 & 2 & 1 & 7.0 & 4 & 3.19 \\
\hline 23 & 2 & 2 & 1 & 7.0 & 5 & 3.00 \\
\hline
\end{tabular}

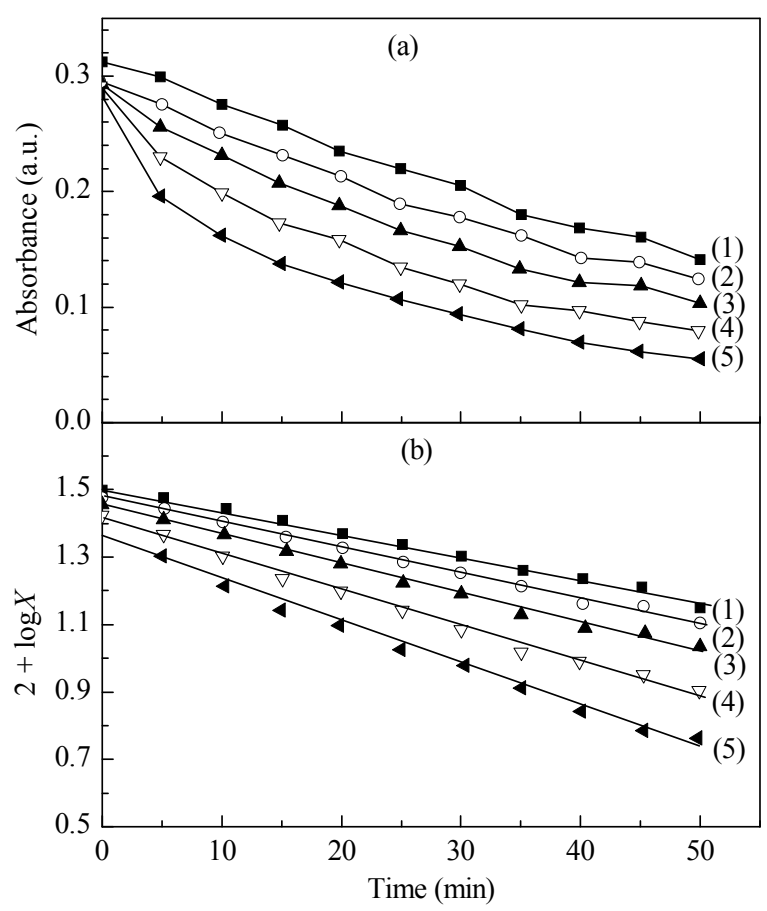

Fig. 5. Absorbance (a) and $\log X$ (b) as functions of time for the deamination of L-leucine at different initial concentrations in the presence of the $\mathrm{Au}$ nanoparticle catalyst. L-leucine concentration $(\mathrm{mol} / \mathrm{L})$ : (1) $1 \times 10^{-7}$; (2) $2 \times 10^{-7}$; (3) $3 \times 10^{-7}$; (4) $4 \times 10^{-7}$; (5) $5 \times 10^{-7}$. Reaction conditions: Au NPs $1 \times 10^{-3} \mathrm{~mol} / \mathrm{L}, \mathrm{H}_{2} \mathrm{O}_{2} 2 \times 10^{-5} \mathrm{~mol} / \mathrm{L}, \mathrm{pH}=$ 7.0 .

to the L-leucine concentration, as can be seen in Fig. 6, which shows the change in absorbance as a function of time (data corresponds to entries 11-16 in Table 1).

\subsection{Effect of $\mathrm{pH}$}

The deamination reaction is $\mathrm{pH}$ sensitive (Table 1, entries 16-18). In acidic, neutral, and basic media, the maximum rate constants for the $\mathrm{Au}$ nanoparticle system were determined to be $3.0 \times 10^{-2}, 4.72 \times 10^{-2}$, and $3.57 \times 10^{-2} \mathrm{~min}^{-1}$, respectively (Fig. 7). The optimum $\mathrm{pH}$ giving the maximum rate constant was found to be 7.0.

\subsection{Effect of ionic strength}

The addition of an inert electrolyte to an ion-ion reaction alters the rate constant depending on the nature of the charge of the reactants. In the present study, $\alpha$-amino acids are neutral and therefore no change in the rate constant is expected in the presence of electrolytes. However, in the presence of $\mathrm{KNO}_{3}$, when the concentrations of $\mathrm{H}_{2} \mathrm{O}_{2}$ and $\mathrm{Au}$ nanoparticles are kept constant, the rate constant increases (Fig. 8 and Table 1, entries 19-22). The positive effect of high ionic strength on the reaction rate indicates that both reactants are similarly charged in the $\mathrm{pH}$ controlled medium. 


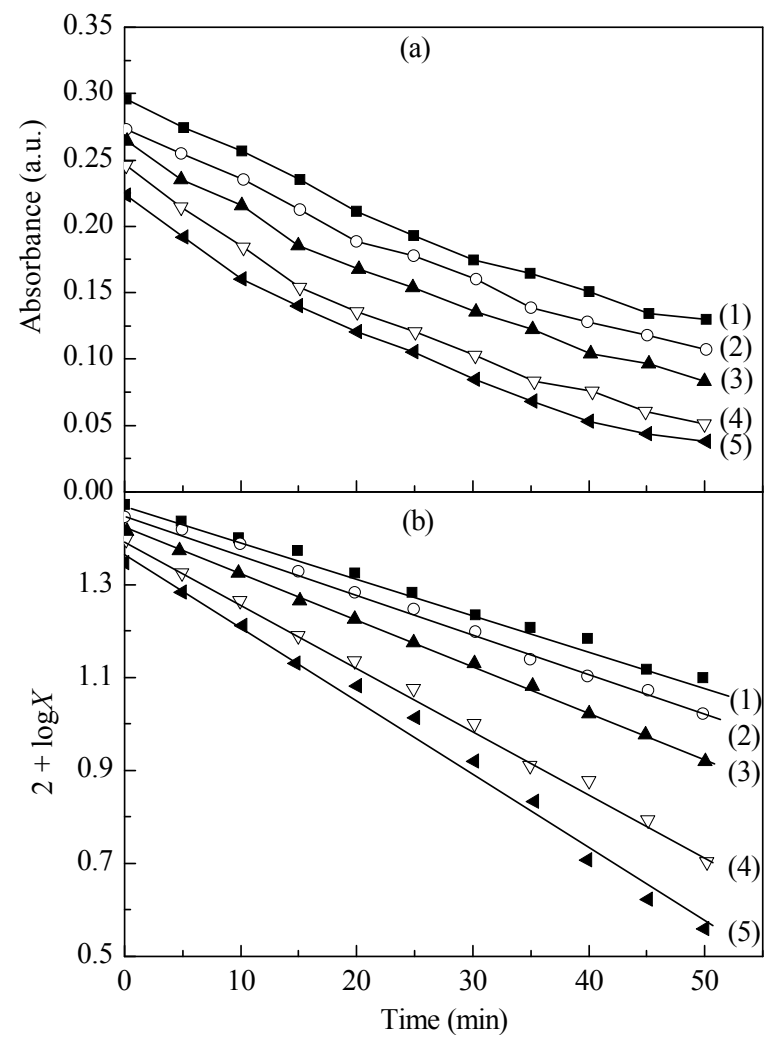

Fig. 6. Absorbance (a) and $\log X$ (b) as functions time for the deamination of L-leucine at different $\mathrm{Au}$ nanoparticle catalyst concentrations. Au NPs concentration (mol/L): (1) $1 \times 10^{-3}$; (2) $2 \times 10^{-3}$; (3) $3 \times 10^{-3}$; (4) $4 \times 10^{-3}$; (5) $5 \times 10^{-3}$. Reaction conditions: L-leucine $2 \times 10^{-7}$ $\mathrm{mol} / \mathrm{L}, \mathrm{H}_{2} \mathrm{O}_{2} 2 \times 10^{-5} \mathrm{~mol} / \mathrm{L}, \mathrm{pH}=7.0$.

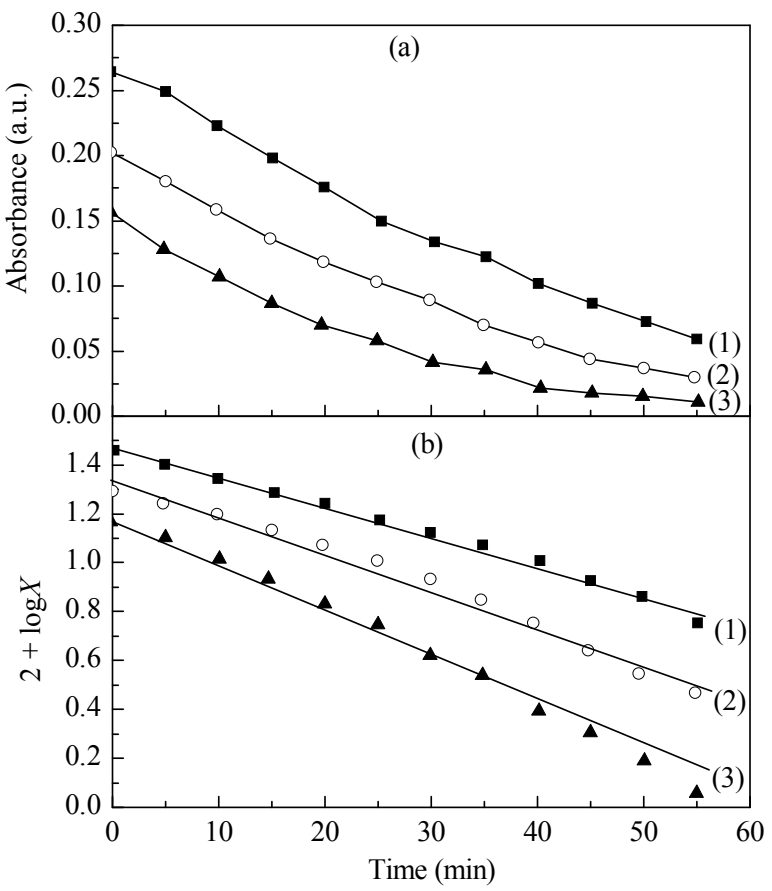

Fig. 7. Absorbance (a) and $\log X$ (b) as functions of time for the deamination of L-leucine at different $\mathrm{pH}$ using the $\mathrm{Au}$ nanoparticle catalyst. $\mathrm{pH}$ value: (1) 7.0; (2) 9.3; (3) 5.2. Reaction conditions: L-leucine $2 \times 10^{-7} \mathrm{~mol} / \mathrm{L}$, Au NPs $1 \times 10^{-3} \mathrm{~mol} / \mathrm{L}, \mathrm{H}_{2} \mathrm{O}_{2} 2 \times 10^{-5} \mathrm{~mol} / \mathrm{L}$.

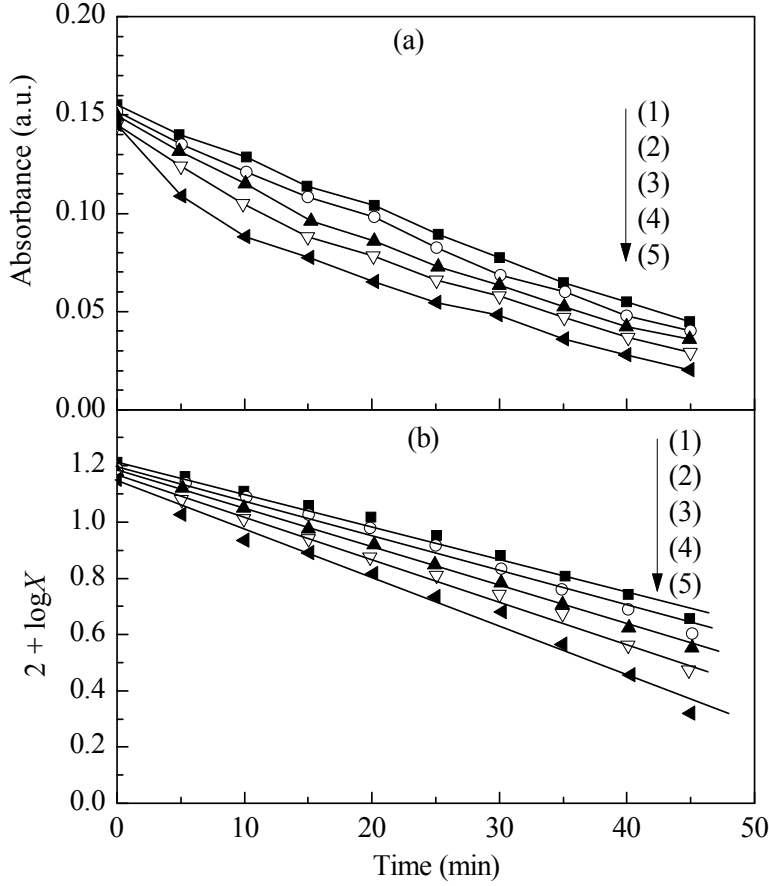

Fig. 8. Absorbance (a) and $\log X$ (b) as functions of time for the deamination of L-leucine in the presence of the Au nanoparticle catalyst at different $\mathrm{KNO}_{3}$ concentrations in aqueous media at $25{ }^{\circ} \mathrm{C} . \mathrm{KNO}_{3}$ concentration (mol/L): (1) $1 \times 10^{-4}$; (2) $2 \times 10^{-4}$; (3) $3 \times 10^{-4}$; (4) $4 \times$ $10^{-4}$; (5) $5 \times 10^{-4}$. Reaction conditions: L-leucine $2 \times 10^{-7} \mathrm{~mol} / \mathrm{L}, \mathrm{Au}$ $\mathrm{NPs} 1 \times 10^{-7} \mathrm{~mol} / \mathrm{L}, \mathrm{H}_{2} \mathrm{O}_{2} 2 \times 10^{-5} \mathrm{~mol} / \mathrm{L}, \mathrm{pH}=7.0$.

\subsection{Effect of different metal nanoparticle catalysts}

The deamination of L-leucine in $\mathrm{H}_{2} \mathrm{O}_{2}$ was then studied using the different mono- and bimetallic nanoparticles. The UV spectra are shown for the case of the monometallic Au nanoparticle catalyst as a function of reaction time in Fig. 9.

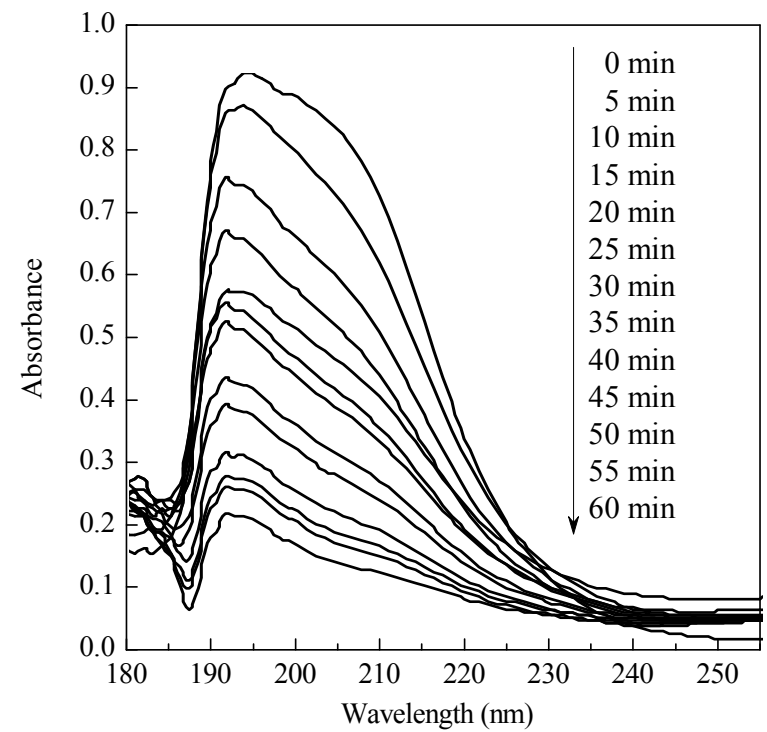

Fig. 9. UV absorption spectra for the deamination of L-leucine in the presence of the Au nanoparticle catalyst in aqueous media at $25^{\circ} \mathrm{C}$. 
The use of bimetallic Au-Ag nanoparticles as the catalyst resulted in higher oxidation conversions than the monometallic nanoparticles, as shown in Table 2. Furthermore, there was no significant difference between the $\mathrm{Au}$ and $\mathrm{Ag}$ nanoparticle catalysts in the selective oxidation of the amino acid.

Table 2 Pseudo-first order rate constants $(k)$ of L-leucine deamination with the different metal nanoparticle catalysts in aqueous media at 25 ${ }^{\circ} \mathrm{C}$

\begin{tabular}{lcc}
\hline \multirow{2}{*}{ Catalyst } & \multicolumn{2}{c}{$k /\left(10^{-2} \mathrm{~s}^{-1}\right)$} \\
\cline { 2 - 3 } & Presence of $\mathrm{H}_{2} \mathrm{O}_{2}$ & Absence of $\mathrm{H}_{2} \mathrm{O}_{2}$ \\
\hline $\mathrm{Au}$ & 7.98 & 6.15 \\
$\mathrm{Ag}$ & 6.72 & 5.86 \\
$\mathrm{Au} / \mathrm{Ag}$ & 12.50 & 10.35 \\
\hline
\end{tabular}

Reaction conditions: L-leucine $2 \times 10^{-7} \mathrm{~mol} / \mathrm{L}, \mathrm{M} 1.24 \times 10^{-3} \mathrm{~mol} / \mathrm{L}$, $\mathrm{H}_{2} \mathrm{O}_{2} 2 \times 10^{-5} \mathrm{~mol} / \mathrm{L}, \mathrm{pH}=7.0$.

\subsection{Mechanism of L-leucine deamination}

The exact mechanism of the homogeneous, metal nanoparticle catalyzed, oxidative L-leucine deamination is unknown. Although certain physical measurements suggest plausible mechanistic paths based on the identification of transient species formed, it is very difficult to isolate and characterize the intermediates from a homogeneous mixture to validate a mechanism beyond any doubt. Moreover, measurement of the oxidation kinetics is complicated by the fact that the oxidation reaction continues in the sample vials during UV-Vis spectroscopic analysis. For these reasons, a simplified and model reaction mechanism is given as follow $(\mathrm{M}=\mathrm{Au}, \mathrm{Ag}$, or $\mathrm{Au} / \mathrm{Ag})$.

$$
\begin{gathered}
\mathrm{M}^{0}+\mathrm{H}_{2} \mathrm{O}_{2} \rightarrow \mathrm{M}^{+}+\mathrm{OH}^{-}+\mathrm{OH}^{-} \\
\mathrm{M}^{+}+\mathrm{H}_{2} \mathrm{O}_{2} \rightarrow \mathrm{M}^{0}+\mathrm{H}^{+}+\mathrm{HOO}^{-}
\end{gathered}
$$

\section{Conclusions}

Monometallic $\mathrm{Au}$ and $\mathrm{Ag}$ nanoparticles, and bimetallic core-shell Au-Ag nanoparticles were prepared in the presence of CTAB surfactant by a wet chemical method. The catalytic activity of the metal nanoparticles prepared was investigated through the oxidation of L-leucine in aqueous solution in the presence and absence of $\mathrm{H}_{2} \mathrm{O}_{2}$. The Au-Ag core-shell bimetallic nanoparticles catalyze the oxidation of the amino acid more efficiently than monometallic $\mathrm{Au}$ and Ag nanoparticles. Kinetics plots obtained from spectrophotometric analysis revealed that the reaction was pseudo-first order with respect to the amino acid. These results have future implications in biochemical and medical fields.

\section{Acknowledgements}

The authors thank to I. I. T. Madras, India, for recording TEM of samples and financial support to the Department from DST-FIST is also acknowledged.

\section{References}

1 Laloo D, Mahanti M K. J Chem Soc, Dalton Trans, 1990: 311

2 Alvarez-Macho M P. Rev Roum Chim, 1993, 38: 999

3 Patnaik P. Handbook of Inorganic Chemicals. New York: McGraw-Hill, 2002

4 Do S H, Batchelor B, Lee H K, Kong S H. Chemosphere, 2009, 75: 8

5 Webb K S, Ruszkay S J. Tetrahedron, 1998, 54: 401

6 Chen M Y, Patkar L N, Chen H T, Lin C C. Carbohyd Res, 2003, 338: 1327

7 Brik M E. Tetrahedron Lett, 1995, 36: 5519

8 Mohajer D, Iranpoor N, Rezaeifard A. Tetrahedron Lett, 2004, 45: 631

9 Johnson P, Taylor R J K. Tetrahedron Lett, 1997, 38: 5873

10 Dixit A, Mungray A K, Chakraborty M. Int J Chem Eng Appl, 2010, 1: 247

11 Mardur S P, Gokavi G S. J Iran Chem Soc, 2010, 7: 441

12 Ghaly M Y, Hartel G, Mayer R, Haseveder R. Waste Management, 2001, 21: 41

13 Sisecioglu M, Gulcin I, Cankaya M, Atasever A, Hilal sehitoglu M, Kaya H B, Ozdemir H. J Med Plant Res, 2010, 4: 1187

14 Wozniak A L, Wojciech J S. Tetrahedron Lett, 1999, 40: 2637

15 Fanjul-Bolado P, Gonzalez-Garcia M B, Costa-Garcia A. Electroanalysis, 2004, 16: 988

16 Abu-Zied B M. Appl Catal A, 2008, 234: 234

17 Campestrini S, Cagnina A. J Mol Catal A, 1999, 150: 77

18 Limburg J, Crabtree R H, Brudvig G W. Inorg Chim Acta, 2000, 297: 301

19 Bagherzadeh M. Tetrahedron Lett, 2003, 44: 8943

20 Santhanalakshmi J, Venkatesan P. J Nanopart Res, 2011, 13: 479

21 Gao J, Fu J, Lin C, Lin J, Han Y, Yu X, Pan C. Langmuir, 2004, 20: 9775

22 Wang X. S, Wang H, Coombs N, Winnik M.A, Manners I. J Am Chem Soc, 2005, 127: 8924

23 Doty R C, Tshikhudo T R, Brust M, Fernig D G. Chem Mater, 2005, 17: 4630 